\title{
Effects of Salicylic Acid in The Normal and Nano Form Against Selected Fungi That Infect Citrus Trees (Citrus sinensis).
}

\author{
Tahsin Shoala ; Gehan, A. Monir ${ }^{2}$ and Basma, H. Amin ${ }^{3}$ \\ ${ }^{1}$ Environmental Biotechnology Department, College of Biotechnology, Misr University for Science and \\ Technology, 6th of October City, Egypt. \\ ${ }^{2}$ Plant Pathology Research Institute, Agricultural Research Centre, 9 Gamaa St, Giza 12619, Egypt. \\ ${ }^{3}$ The Regional Center for Mycology and Biotechnology (RCMB), Al-Azhar University, Egypt.
}

\begin{abstract}
Evaluation of the potential antifungal activity of salicylic acid in the normal and nano form on the pathogenic fungi (Alternaria alternata and Penicillium digitatum) causing citrus leave spots and fruit decay was studied under in vitro and in vivo conditions. Characterization of prepared salicylic acid nanoparticles (SA NPs), i.e., size distribution and the stability showed that, size distribution range mainly within $8-40 \mathrm{~nm}$ as well as hydrodynamic size for produced nanoparticles is $8-40 \mathrm{~nm}$. Salicylic acid nanoparticles and bulk material at 0.5 and $1 \mathrm{mM}$, in vitro significantly reduced the mycelial growth for Alternaria alternata and Penicillium digitatum, whereas there was not a significant difference between salicylic acid nanoparticles and bulk material, however significant changes of the linear growth were noticed between the low and the high concentrations. Examinations using transmission electron microscopy (TEM) showed hyphal and conidial deformations in addition to changes in cellular structure of A. alternata and Penicillium digitatum when treated with salicylic acid nanoparticles at $1 \mathrm{mM}$ concentration. In case of Alternaria alternata, an increasing of the spinulose conidial cell wall and cell membrane showed and appearance of numerous vacuoles in the cytoplasm with undefined cytoplasmic organelles as well as well-defined ultrastructure organelles of the mycelium, meanwhile in case of Penicillium digitatum salicylic acid nanoparticles exhibited a disrupted cell wall (CW) and several invaginations in the cytoplasmic membrane; shrinkage and decrease in thickness with completely cytoplasmic organelles leakage and accumulation of salicylic acid nanoparticles. The effect of salicylic acid in the normal and nano form were evaluated under field conditions against phytopathogenic fungi Alternaria alternata and Penicillium digitatum on Valencia orange in Ismailia governorate during growing season 2019/2020, salicylic acid in the normal and nano form, significantly reduced the percentages of disease incidence for both Alternaria alternata and Penicillium digitatum compared with the untreated control under field conditions.
\end{abstract}

Keywords: Citrus, Citrus sinensis, Alternaria alternata, Penicillium digitatum, salicylic acid. 


\section{Introduction}

Citrus sinensis (L.) is one of the major commercial fruit plants which, due to its high content of vitamin $\mathrm{C}$ and potential antioxidant, is widely eaten as fresh fruit and juice (Gorinstein et al., 2001). The cultivar in over 137 countries on six continents is primarily grown in tropical or subtropical regions of the world (Ismail and Zhang, 2004). Sweet orange is an important fruit crop that demands excellent quality and shelf life in international trade. Regrettably, several pathogens are known to attack which affect the quality of the fruit. In developing countries, where fresh fruit is adequately protected and managed properly, losses during transit and storage may be over 50\% (Eckert and Ogawa, 1985). Spoilage microorganisms may be introduced in the cultivation on the seed itself, during field growth, harvesting, handling and storage and distribution (Barth et al., 2009).

Most citrus fruits are infected with a variety of bacteria and fungi, but only a small proportion of them are resistant to plant pathogenic microorganisms due to a specific environmental condition. Extensive applications of agrochemicals to maintain yield and crop protection from plant pathogenic microorganisms have sparked thoughtful brainstorming topics. Researchers and policymakers are anticipating resolutions to protect the environment by reducing pesticide consumption while reaching preferred agricultural yield to feed the world's ever-growing population (Tilman et al., 2002). Agrochemicals used extensively in agriculture contribute to global warming and enhance the likelihood of harmful bacteria developing resistance (Jang $\boldsymbol{e t}$ al., 2014; Hahn $\boldsymbol{e t}$ al., 2014). To deal with the forthcoming multi-dynamic stressors, we need to devise a novel method for controlling phytopathogens, increasing plant immunity, strengthening the signalling network, and promoting plant development (Kushalappa et al., 2016; Andolfo et al., 2016).

Salicylic acid (SA) is a naturally occurring phenolic molecule found in plants that plays an important role in the signalling pathways that lead to the beginning of systemic acquired resistance (SAR). Up-regulation of seed germination, respiration, photosynthesis, vegetative development, flower formation, senescence, thermogenesis, and cellular redox homeostasis are just a few of the pathways in plants where SA plays a vital role (Malamy et al., 1992; Raskin et al., 1990; Vlot et al., 2009; Khan et al., 2015; Rivas-San and Vicente, 2011; Kumar, 2014). 
External use of SA in different parts of the plant stimulates many metabolic pathways and can be an alternative approach to treating diseases and increasing plant productivity. The bioactivity of external use of SA in plants can be affected by various factors, such as concentration, duration of treatment, age of plants, species, and target areas (Revas San and Vicente, 2011; Kumar Kumar, 2014). SA plays a dual role in plant protection, leading to different pathways of resistance, and can also have a positive effect on phytopathogens.

Nanotechnology is taking the world to a new era in the management and diagnosis of plant pathogens. External use of various natural nanomaterials is an important magical solution to many environmental problems (Shoala, 2018) to fight plant pathogens, enhance plant protection and produce plants without harming the environment. Thus, our current research focuses on the use of nano- and general-form salicylic acid (SA) to increase activity against plant pathogens and enhance plant protection and production using small amounts of SA. To fill a major research gap on SA in-vitro use to achieve its dosage release for a long-term effect on a permanent basis.

\section{Material and Methods}

\section{Source of the tested fungal isolates:}

The tested fungi Alternaria alternata and Penicillium digitatum were previously examined for their pathogenic ability, as all the tested fungi were pathogenic, with varied degree to citrus leaves and showed also different level of disease symptoms on fruits, (Abdelmalek and Salaheldin, 2016).

\section{Antifungal activity of salicylic acid in the nano and normal form}

In this study the fungal pathogens Alternaria alternata and Penicillium digitatum were grown on potato dextrose agar (PDA) and incubated at $28 \pm 2{ }^{\circ} \mathrm{C}$ for 7 days. In vitro assay was carried out on PDA treated with 0.5 and $1 \mathrm{mM}$ of salicylic acid in the nano and normal form. Five $\mathrm{mL}$ of it was poured into the media before plating into each $90 \times 15 \mathrm{~mm}$ Petri dish. The media containing salicylic acid nanoparticles was incubated at room temperature. After $48 \mathrm{hr}$ of incubation, an agar plugs of $5 \mathrm{~mm}$ diameter containing fungi was inoculated simultaneously at the center of each Petri dish and incubated at $28 \pm 2^{\circ} \mathrm{C}$. After 2 wk of incubation, inhibition zones were measured. The test was repeated twice, and each treatment replicated three times (Kabir et al., 2011). 
The inhibition rate (\%) was calculated by using the following formula

$$
\text { Inhibition rate }(\%)=\frac{\mathrm{R}-\mathrm{r}}{\mathrm{R}} \times 100
$$

That:

$\mathrm{R}=$ radial growth of fungi in control plate

$\mathrm{R}=$ radial growth of fungi in salicylic acid in the nano and normal form treated plates.

\section{Salicylic acid nanosynthesis}

Salicylic acid was acquired from Sigma-Adrich (CAS number: 20283-92-5) and dissolved in $10 \mathrm{ml} \mathrm{100 \%} \mathrm{ethanol} \mathrm{before} \mathrm{being} \mathrm{sonicated} \mathrm{for} \mathrm{an} \mathrm{hour} \mathrm{at} \mathrm{ambient} \mathrm{temperature}\left(25^{\circ} \mathrm{C}\right)$ with an ultrasonic power and frequency of $50 \mathrm{kHz}$ (XUBA3Analogue Ultrasonic Bath, Grant Company).

\section{Dynamic light scattering (DLS)}

Salicylic acid nanoparticle distribution and size were measured at room temperature using a dynamic light scattering method with a Zetasizer Nano ZS (Malvern Instruments, UK). 30 $\mu 1$ of the nanoparticle was diluted with $3 \mathrm{ml}$ of water at $25^{\circ} \mathrm{C}$ prior to measurement. The mean of the Z-average of three independent batches of nanoparticles was used to calculate particle size.

\section{Transmission Electron Microscopy of salicylic acid nanoparticles (SA NPs):}

For TEM analysis, a drop of the solution was placed on the carbon coated copper grids (CCG) and dried by allowing water to evaporate at room temperature. Electron micrographs were obtained using JEOL GEM-1010 transmission electron microscope at $70 \mathrm{kV}$ at The Regional center for Mycology and Biotechnology, (RCMB) Al- Azhar University (Amin and ElSharkawy, 2019).

\section{Electron microscopy ultrastructure examination}

For TEM preparation, the samples were fixed in 3\% glutaraldehyde, rinsed in phosphate buffer, and post-fixed in potassium permanganate solution for $5 \mathrm{~min}$. at room temperature. The samples were dehydrated in an ethanol series ranging from $10 \%$ to $90 \%$ for $15 \mathrm{~min}$ in each alcohol dilution and finally with absolute ethanol for $30 \mathrm{~min}$. Samples were infiltrated with epoxy resin and acetone through a graded series till finally in pure resin. Ultrathin sections were collected on copper grids. Sections were then double stained in uranyl acetate followed by lead citrate. Stained sections were observed with a JEOL - JEM 1010 transmission electron 
microscope at $70 \mathrm{kV}$ at The Regional Center for Mycology and Biotechnology (RCMB), AlAzhar University (Amin, 2016; Elsherbiny et al., 2020).

\section{Field trials and data analysis}

To determine the efficacy of salicylic acid normal and nanoparticles formula against some disease on Valencia orange in the field, an experiment was carried out in Om Qamar Village Cairo Ismailia Desert Road. during growing season 2019/2020, salicylic acid normal and nanoparticles were used at 0.5 and $1.0 \mathrm{mM}$ simultaneously. It was applied on the tree beginning in February every fifteen days the treatment was repeated three times. Results were obtained monthly from February to December. Distilled water was used as a negative control.

Disease incidence (\%) of leaf spots was calculated by counting the numbers of infected leaves out of 150 leaves among the treated plants in field trials. Each experiment was repeated three times. To assess disease incidence of fruit rots, a total of 102 plants were randomly selected from the orchards. A sample size of ten (10) plants and fifty (50) fruits were selected from orchard of Citrus to record disease incidence. Computations were achieved with the help of the following formulae (Safdar et al., 2010).

$$
\text { Disease Incidence }(\%)=\frac{\text { No. of infected fruits }}{\text { Total No. of fruits }} \times 100
$$

\section{Statistical analysis}

To determine significant differences between treatments, the data was subject for the Variance Analysis (ANOVA) and the MultiRange Test by Duncan was used. The scan was carried out using Windows (IBM Inc., Chicago, IL) SPSS Statistical Data Editor 23.0 and P < 0,05 was considered significantly differently.

\section{Results}

\section{Characterization of SA nanoparticles}

Dynamic light scattering technique was performed to understand the size distribution and the stability of prepared SA nanoparticles (Fig 1). Dynamic light scattering technique was performed to understand the size distribution and the stability of prepared SA NPs has a size distribution range mainly within 9.96-27.3 $\mathrm{nm}$ as shown in (Fig 2, Fig 3). An average hydrodynamic size for produced nanoparticles is $9.96-27.3 \mathrm{~nm}$. 


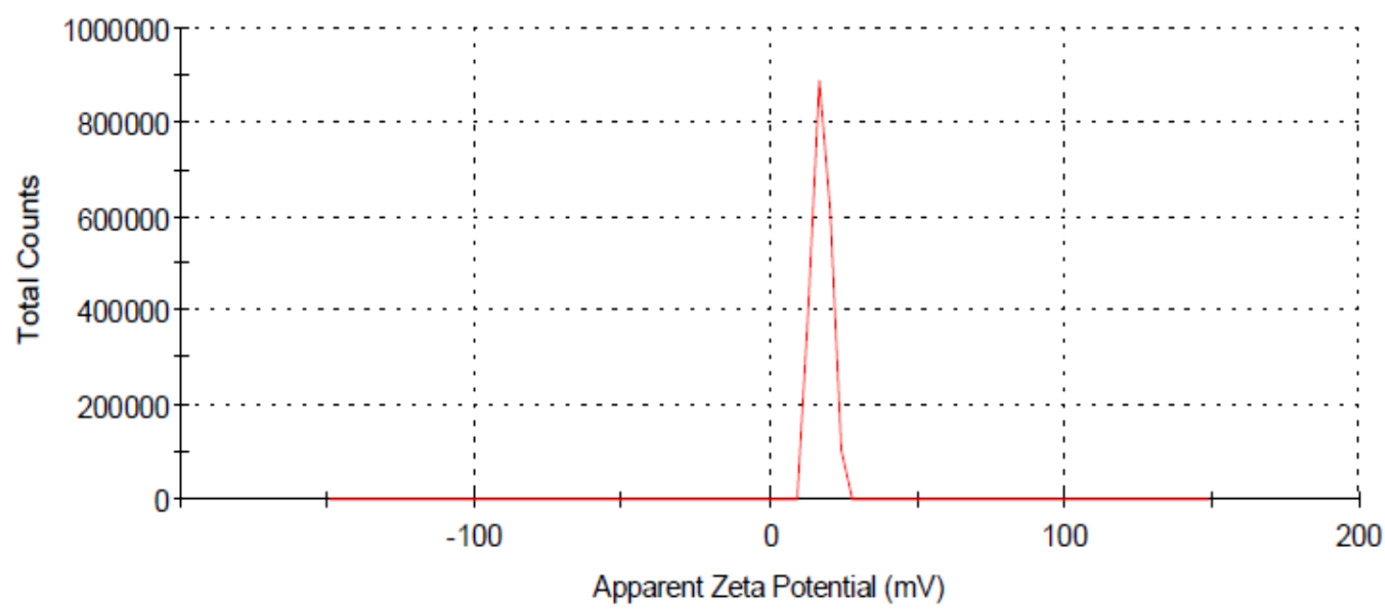

Fig. 1. Zeta potential values of salicylic acid nanoparticles.

Size Distribution by Volume

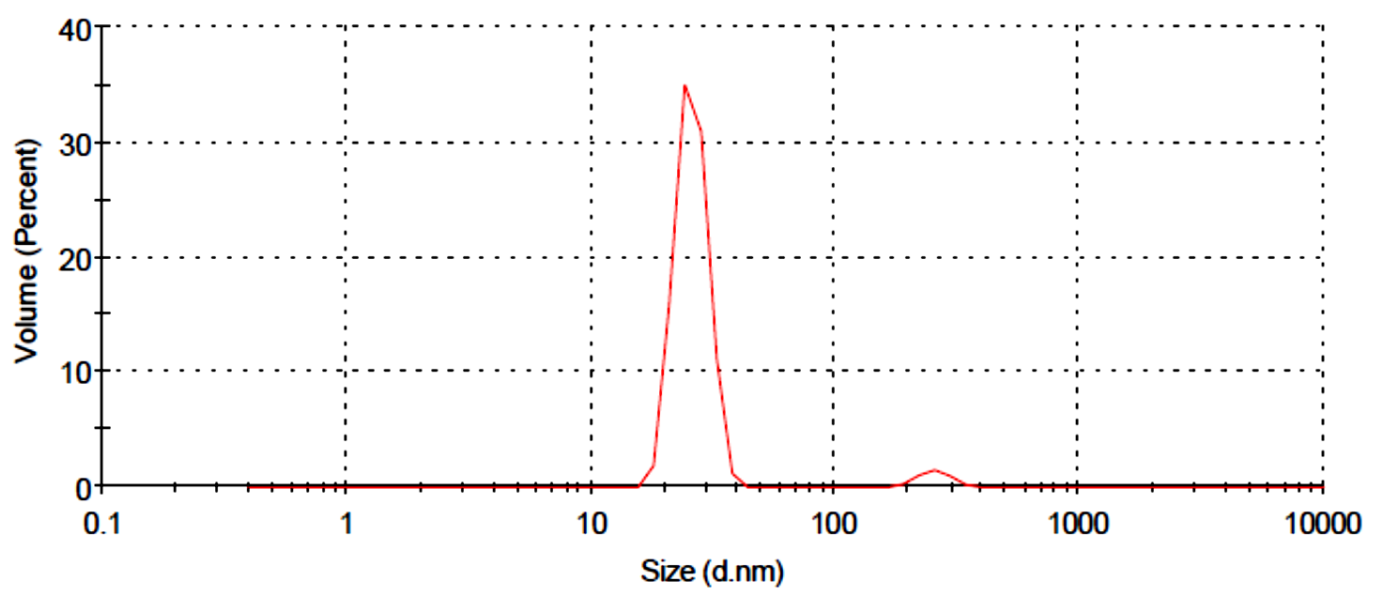

Fig 2. $Z$ average size of SA NPs, $40 \mathrm{~nm}$. 


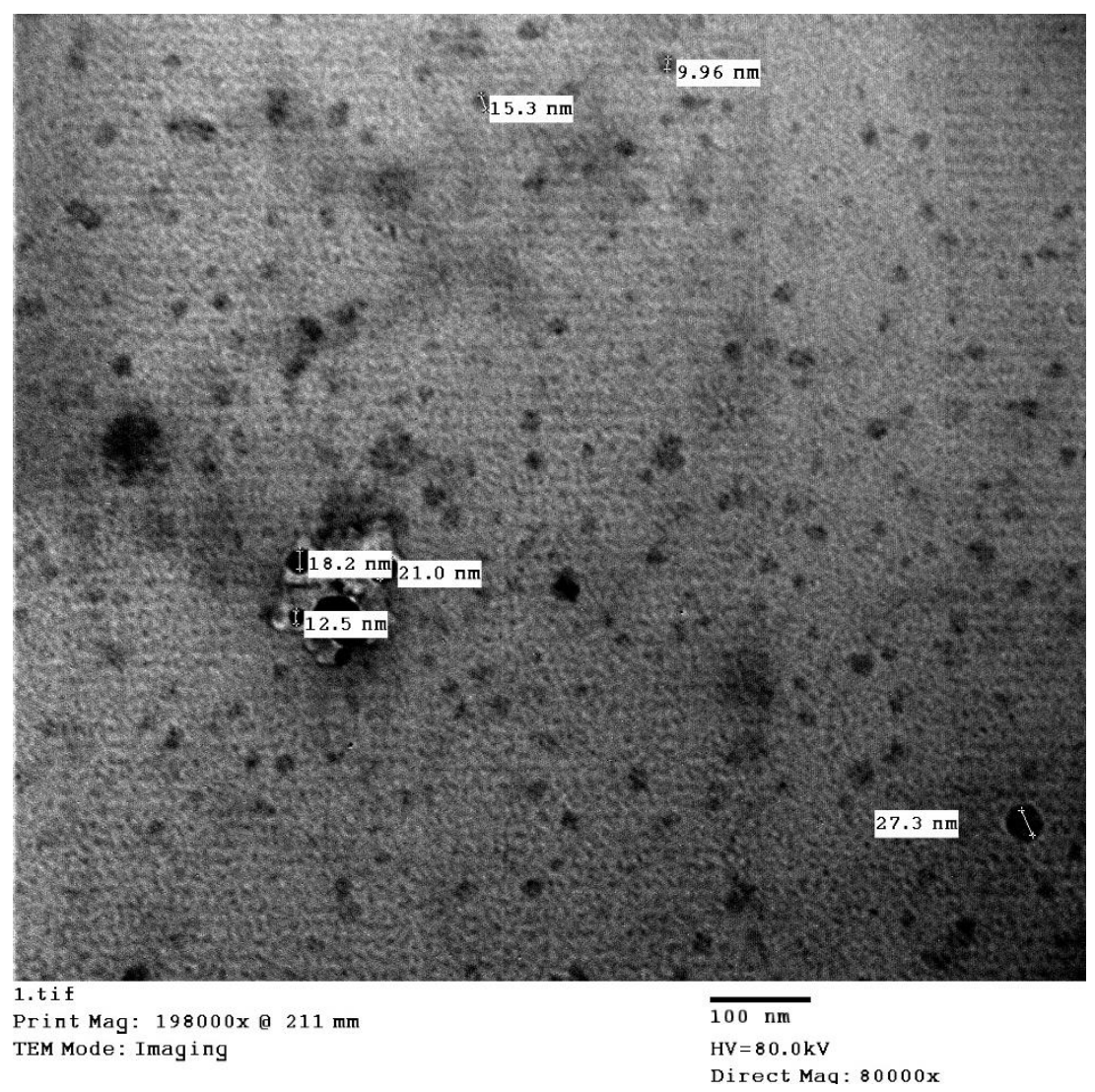

Fig 3. Transmission electron microscopy (TEM) view of formulated SA nanoparticles.

\section{Antifungal effect of salicylic acid on A. alternata growth in vitro:}

When compared to the control, all concentrations of SA nanoparticles and bulk material suppressed A. alternata mycelial growth on PDA medium. However, the treatments at 0.5 and $1 \mathrm{mM}$ had varying effects on A. alternata growth (Table 1). SA nanoparticles at $1 \mathrm{mM}$ were more effective than other tested concentrations in inhibiting A. alternata mycelial growth. Meanwhile, SA at $0.5 \mathrm{mM}$ inhibited A. alternata only slightly. Furthermore, at $0.5 \mathrm{mM}$, there were no significant differences between SA nanoparticles and bulk material. While significant discrepancies in linear growth of A. alternata were detected between the low and the high concentrations of the two SA forms. 
Table 1. Antifungal effect of salicylic acid on the growth $(\mathrm{mm})$ of A. alternata in vitro.

\begin{tabular}{lccc}
\hline \multirow{2}{*}{ Treatments } & Conc. & \multicolumn{2}{c}{ Linear growth } \\
\cline { 3 - 4 } & $\mathrm{mM}$ & $\mathrm{Mm}$ & Ef \% \\
\hline \multirow{2}{*}{ Salicylic acid Bulk material } & 0.5 & $79.5 \mathrm{~b}$ & 11.66 \\
& 1 & $52.5 \mathrm{c}$ & 41.66 \\
Salicylic acid nanoparticles & 0.5 & $71.00 \mathrm{~b}$ & 21.11 \\
Control & 1 & $46.75 \mathrm{c}$ & 48.05 \\
\end{tabular}

Within each column, same letter/s indicates no significant difference among treatments at $(\mathbf{P}<0.05)$. $\mathbf{m m}=$ millimetres. $\quad$ Ef $\%=$ Efficacy Control (un-treated).

Antifungal effect of salicylic acid on $P$. digitatum growth in vitro:

The mycelial growth of $P$. digitatum on PDA medium has been suppressed compared to the control by all concentrations of SA nanoparticles and bulk material. Nevertheless, different suppression effects were observed with $P$. digitatum growth at 0,5 and $1 \mathrm{mM}$. (Table 2). Treatment for SA nanoparticles at $1 \mathrm{mM}$ were more effective than other concentrations tested in inhibiting $P$. digitatum mycelial growth. In the meantime, SA with 0,5 $\mathrm{mM}$ has shown low inhibition of $P$. digitatum. Furthermore, the data showed that the SA nanoparticles and bulk material were recorded at $0.5 \mathrm{mM}$ without any significant differences. However significant changes in linear growth of $P$. digitatum were noticed between the low and the high concentrations of the two SA forms.

Table 2. Antifungal effect of salicylic acid on the growth $(\mathrm{mm})$ of $P$. digitatum in vitro.

\begin{tabular}{lccc}
\hline \multirow{2}{*}{ Treatments } & Conc. & \multicolumn{2}{c}{ Linear growth } \\
\cline { 3 - 4 } & $\mathrm{mM}$ & $\mathrm{Mm}$ & $\mathrm{Ef} \%$ \\
\hline \multirow{2}{*}{ Salicylic acid Bulk material } & 0.5 & $81.5 \mathrm{~b}$ & 9.44 \\
& 1 & $60.5 \mathrm{c}$ & 32.77 \\
Salicylic acid nanoparticles & 0.5 & $78.00 \mathrm{~b}$ & 13.33 \\
Control & 1 & $54.75 \mathrm{c}$ & 39.16 \\
\hline
\end{tabular}

Within each column, same letter/s indicates no significant difference among treatments at $(\mathbf{P}<0.05)$. mm= millimetres. Ef $\%=$ Efficacy Control (un-treated). 

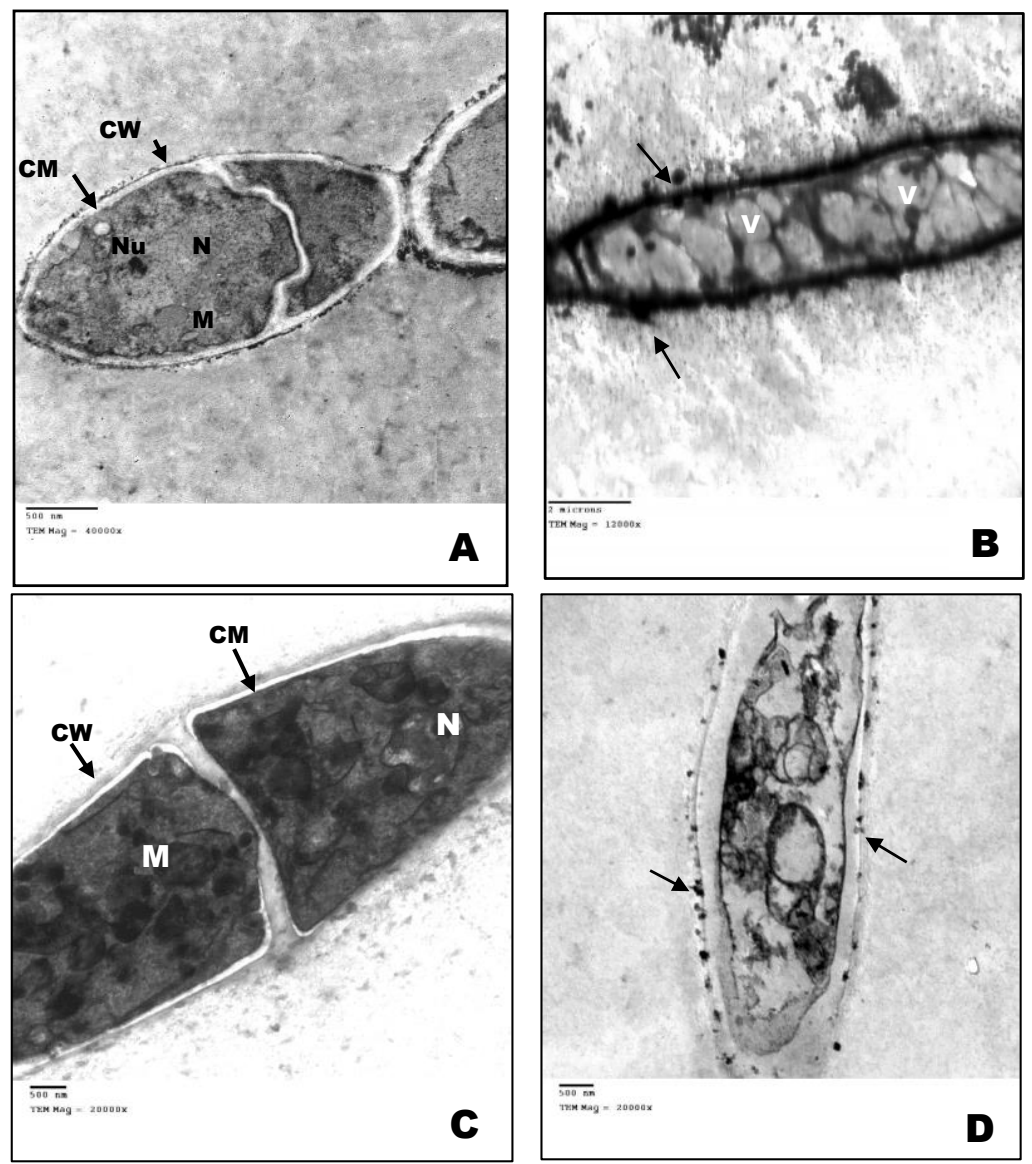

Fig 4. TEM micrograph of Alternaria alternata. A; control, B; treated with salicylic acid nanoparticles and Penicillium digitatum C; control, D; treated with salicylic acid nanoparticles. CW: Cell Wall, CM: Cell membrane, M: Mitochondria, N: Nucleus.

In Alternaria alternata ultrathin sections at 7 days of growth, there were clear changes according to the treated with salicylic acid nanoparticles at $1 \mathrm{mM}$ concentration; the spinulose conidial cell wall and cell membrane showed increasing in thickness with accumulation of salicylic acid nanoparticles (arrows) and appearance of numerous vacuoles (V) in the cytoplasm with undefined cytoplasmic organelles ( Fig 4B) compared with the control (without treatments); mycelium that showed well-defined ultrastructure organelles; nucleus $(\mathrm{N})$ with its nucleolus $(\mathrm{Nu})$, mitochondria $(\mathrm{M})$ and an even cell wall $(\mathrm{CW})$ and cell membrane (CM); (Fig 4A).

The untreated (control) Penicillium digitatum ultrathin sections exhibit a compact cell wall $(\mathrm{CW})$, continuous cytoplasmic membrane $(\mathrm{CM})$, homogeneous and electron-dense cytoplasm with normal organelles appearance; (M), nucleus (N) (Fig 4C). 
By contrast, Penicillium digitatum ultrathin sections cultured with $1 \mathrm{mM}$ concentration salicylic acid nanoparticles exhibited a disrupted cell wall (CW) and several invaginations in the cytoplasmic membrane; shrinkage and decrease in thickness with completely cytoplasmic organelles leakage and accumulation of salicylic acid nanoparticles (arrows) (Fig 4D).

Table 3. Effect of salicylic acid in the normal and nano form against phytopathogenic fungi Alternaria alternata and Penicillium digitatum on Valencia orange in Ismailia governorate.

\begin{tabular}{|c|c|c|c|}
\hline \multirow[t]{2}{*}{ Treatments } & \multirow{2}{*}{$\begin{array}{c}\text { Concentrations } \\
\mathrm{mM}\end{array}$} & \multicolumn{2}{|c|}{$\%$ Disease incidence } \\
\hline & & $\begin{array}{l}\text { Alternaria alternata } \\
\text { (Leaf spot) }\end{array}$ & $\begin{array}{l}\text { Penicillium digitatum } \\
\text { (Fruit rot) }\end{array}$ \\
\hline \multirow{2}{*}{$\begin{array}{c}\text { Nano salicylic acid } \\
\text { SA NPs }\end{array}$} & 0.5 & 7 & 11 \\
\hline & 1 & 5 & 8 \\
\hline \multirow{2}{*}{$\begin{array}{l}\text { Normal Salicylic acid } \\
\text { Bulk }\end{array}$} & 0.5 & 13 & 14 \\
\hline & 1 & 9 & 10 \\
\hline Control & --- & 28 & 27 \\
\hline
\end{tabular}

Table (3) showed that nano and normal salicylic acid decreased the percentage of disease incidence for both Alternaria alternata and Penicillium digitatum compared to the control (Table 3).

\section{Discussion}

The main purpose of this study was to assess the effectiveness of SA treatment for leaf spot and fruit rot diseases, incidence of diseases, morphological and fungal organelles in two forms (nanoparticles and bulk materials). SA NPs are produced and afterwards analyzed by the dynamic method of light diffusion. The results showed the development of large and average nanoscale dispersed particles. In this work we investigated the improved activity of SA NPs in the suppression of fungal growth, changes in fungal property, reduced disease severity, incidence, and increased plant defense response compared with their bulk equivalents. In the improved action mode of SA NPs nanosize effects, which are clearly different from those of their large counterparts, might be explained (Aslani et al., 2014). The increased surface area and the tiny size of the nanoparticles enhance their solubility and dispersion into biodiversity samples (Chen et al., 2020). In vitro results have shown that the linear growth of A. alternata and Penicillium digitatum has been significantly suppressed by both forms of SA therapy. A significant inhibition occurred when the level of SA is increased. This finding is well supported by several previous studies that show that SA can prevent fungal growth directly in vitro (Panahirad et al., 2014; Qi et al., 2012). 
The linear growth of $A$. solani, with an increase in salicylic and citric acid concentrations, was significantly decreased. SA treatment has suppressed mycelial growth and conidial sprouting of Fusarium mangiferae (Kumar \& Bains, 2018). SA treatment at $2 \mathrm{mM}$ showed direct fungal toxicity on Monilinia Fructicola and considerably inhibited mycelial growth and in vitro spore germination (Yao \& Tian, 2005). Several potential mechanisms proposed by Dieryckx et al. (2015) represented that the fungal growth inhibition following SA applications. These include (i) accumulation of Reactive Oxygen Species (ROS) and suppressing enzymes involved in ROS detoxifications, (ii) alterations in mitochondrial respiration by disturbing the the Krebs cycle, and (iii) damage to fungal cell wall integrity by reducing the fungal cell volumes of Cerato-platanine-related protein (CPP). CPP are small, produced proteins produced by the fungi and play a major role in fungal growth (Gaderer et al., 2014). PR-1 proteins may be involved in cell wall thickening and resist pathogen spread in the apoplast, according to one proposed function (Chmielowska et al., 2010). Some research has shown that $\beta$-1,3-glucanase proteins can act directly by degrading the pathogen cell wall, or indirectly by generating signal molecules that act as a defence elicitor.

\section{Conclusion}

This study showed that the exogenous application of SA in nanoparticles could increase the defence response of navel orange, which interpreted the application to decrease the severity of leaf spot and fruit rot. Implementing SANPs in agricultural practises may minimise the scope of chemical controls and that finding is intended to pave the way for a better and more sustainable method of disease control and reduction in losses of yield.

\section{References}

Abdelmalek, G.A.M. and Salaheldin, T.A. (2016). Silver nanoparticles as a potent fungicide for citrus phytopathogenic fungi. Journal of Nanomedicine Research, 3(5): 00065.

Amin, B.H. (2016). Isolation and characterization of antiprotozoal and antimicrobial metabolite from Penicillium roqueforti. Afr. J. Mycol. \& Biotech. 21(3): 13-26.

Amin, B.H. and El-Sharkawy, R.M. 2019. Bactericidal Activity of Silver Nanoparticles Produced by Fusarium solani against the Multidrug-Resistant Bacteria. RJPBCS; 10(6), 203- 211. ISSN: 0975-8585.

Andolfo, G.; Iovieno, P.; Frusciante, L. and Ercolano M. (2016). Genome-Editing Technologies for Enhancing Plant Disease Resistance. Frontiers in Plant Science (December): 1813. doi: org:10.3389/fpls.2016.01813. 
Aslani, F.; Bagheri, S.; Muhd Julkapli, N.; Juraimi, A. S.; Hashemi, F.S.G. and Baghdadi, A. (2014). Effects of engineered nanomaterials on plants growth: an overview. The Scientific World Journal, 2014, 641759. https://doi. org/10.1155/2014/641759.

Barth, M.; Hankinson, T.R.; Zhuang, H. and Breidt, F. (2009). Microbiological Spoilage of Fruits and Vegetables. W.H. Sperber, M.P. Doyle (eds.), Compendium of the Microbiological Spoilage of Foods and Beverages, Food Microbiology and Food Safety. C Springer Science Business Media, LLC, Pp135-183.

Barnett, H.L and Hunter, B.B. (1972). Illustrated Genera of Imperfect Fungi. Burger Publishing Minneapolis Minnesota. $3^{\text {rd }}$ edition. P: 116-117.

Chen, J.; Wu, L.; Lu, M.; Lu, S.; Li, Z. and Ding, W. (2020). Comparative study on the fungicidal activity of metallic $\mathrm{MgO}$ nanoparticles and macroscale $\mathrm{MgO}$ against soilborne fungal phytopathogens. Frontiers in Microbiology, 11, 365. https://doi.org/10.3389/fmicb.2020.00365.

Chmielowska, J.; Veloso, J.; Gutiérrez, J.; Silvar, C. and Díaz, J. (2010). Cross-protection of pepper plants stressed by copper against a vascular pathogen is accompanied by the induction of a defence response. Plant Science, 178, 176-182. https://doi.org/10.1016/j.plantsci.2009.11.007.

Dieryckx, C.; Gaudin, V.; Dupuy, J. W.; Bonneu, M.; Girard, V. and Job, D. (2015). Beyond plant defense: insights on the potential of salicylic and methyl salicylic acid to contain growth of the phytopathogen Botrytis cinerea. Frontiers in Plant Science, 6: 859-859.

Eckert, J. and Ogawa, J. (1985). The chemical control of postharvest diseases. Subtropical and tropical fruits Annual Review of Phytopathology, 23: 421-454.

Elsherbiny, A. E.; Basma, H. A.; Bushra, A., Kathryn L. K.; and Joan W. B. (2020). Trichoderma Volatile Organic Compounds as a Biofumigation Tool against Late Blight Pathogen Phytophthora infestans in Postharvest Potato Tubers. J. Agric. Food Chem. 2020, 68, 8163-8171.

Embaby E. M.; Hazaa, M.; Hagag, L.F.; Ibrahim, T.E. and Abd El-Azem, F.S. (2013 A) Decay of Some Citrus Fruit Quality Caused by Fungi and their Control: III- Control Blue and Green mould decay by using some alternative fungicides. J. Appl. Sci. Res., 9(8): 50865096.

Embaby E. M.; Hazaa, M.; Hagag, L.F.; Ibrahim, T.E. and Abd El-Azem, F.S. (2013 B). Decay of Some Citrus Fruit Quality Caused by Fungi and their Control: II- Control Alternaria rot or core rot decay by using some alternative fungicides. J. Appl. Sci. Res., 9(11): 56715678 .

Embaby E. M.; Hazaa, M.; Hagag, L.F.; Ibrahim, T.E. and Abd El-Azem, F.S. (2013 C) Decay of Some Citrus Fruit Quality Caused by Fungi. J. Appl. Sci. Res., 9(11): 5920-5929, 2013.

Gaderer, R.; Bonazza, K. and Seidl-Seiboth, V. (2014). Ceratoplatanins: A fungal protein family with intriguing properties and application potential. Applied Microbiology and Biotechnology, 98, 4795-4803. https://doi.org/10.1007 /s00253-014-5690-y.

Gorinstein, S.; Martin, B.O.; Park, Y.; Haruenkit, R.; Lojek, A.; Milan, I.; Caspi, A.; Libma, I. and Traktenberg, S. (2001). Comparison of some biochemical characteristics of different citrus fruits. Food Chemistry, 74(3) 309-315. 
Hahn, M.; Geisthardt, M.; and Brühl, C.A. (2014). Effects of herbicide-treated host plants on the development of Mamestra brassicae L. caterpillars. Environ. Toxicol. Chem. 33, 2633-2638. doi: 10.1002/etc.2726.

Ismail, M. and Zhang, J. (2004). Postharvest citrus diseases and their control. Outlook of Pest Management, 15: 29-35.

Jang, J.; Di, D.Y.W.; Lee, A.; Unno, T.; Sadowsky, M.J. and Hur, H.G. (2014). Seasonal and genotypic changes in Escherichia coli phylogenetic groups in the Yeongsan River basin of South Korea. PloS One 9: 5-12.

Kabir. L.; Kim S.W.; Jung J.H.; Kim S.B.; Kim, K.S. and Lee, Y.S. (2011). Application of Silver Nanoparticles for the Control of Colletotrichum Species In Vitro and Pepper Anthracnose Disease in Field. Mycobiology 39(3): 194-199 (2011)

Khan, M.I.R.; Fatma, M.; Per, T.S.; Anjum, N.A. and Khan, N.A. (2015). Salicylic acidinduced abiotic stress tolerance and underlying mechanisms in plants. Front. Plant Sci. 6: 462. doi: 10.3389/fpls.2015.00462.

Kim, S.W.; Jung, J.H.; Lamsal, K.; Kim, Y.S.; Min, J.S. and Lee, Y.S. (2012). Antifungal effects of silver nanoparticles (Ag NPs) against various plant pathogenic fungi. Korean Soc. Mycol. Mycobiol., 40: 53-58.

Kumar, D. (2014). Salicylic acid signalling in disease resistance. Plant Sci. 228: 127-134. doi: 10.1016/j.plantsci.2014.04.014.

Kumar, V. and Bains, G. (2018). Effect of salicylic acid on mycelial growth and conidial germination of two isolates of Fusarium mangiferae. International Journal of Current Microbiology and Applied Sciences, 7: 3704-3710.

Kushalappa, A.C.; Yogendra, K.N. and Karre, S. (2016). Plant Innate Immune Response: Qualitative and Quantitative Resistance. Critical Reviews in Plant Sciences 35(1): 38-55. doi:10.1080/07352689.2016.1148980.

Malamy, J.; Hennig, J. and Klessig, D.F. (1992). Temperature-dependent induction of salicylic acid and its conjugates during the resistance response to tobacco mosaic virus infection. Plant Cell, 4: 359. doi: 10.1105/tpc.4.3.359.

Morones, J.R.; Elechiguerra, J.L.; Camacho, A.; Holt, K.; Kouri, J.B.; Ramirez, J.T. and Yacaman, M.J. (2005). The bactericidal effect of silver nanoparticles. Nanobiotechnol., 16: 2346-2353.

Norman, S. and Hongda, C. (2013). IB in depth. Special section on nanobiotechnology, Part 2. Ind. Biotechnol., 9: 17-18.

Patel, N.; Desai, P.; Patel, N.; Jha, A. and Gautam, H.K. (2014). Agronano technology for plant fungal disease management: A Review. Int. J. Curr. Microbiol. App. Sci., 3(10): 71-84.

Panahirad, S.; Zaare-Nahandi, F.; Mohammadi, N.; Alizadeh Salteh, S. and Safaie, N. (2014). Effects of salicylic acid on Aspergillus flavus infection and aflatoxin B1 accumulation in pistachio (Pistacia vera L.) fruit. Journal of the Science of Food and Agriculture, 94: 1758-1763. https://doi. org/10.1002/jsfa.6488.

Qi, P.F.; Johnston, A.; Balcerzak, M.; Rocheleau, H.; Harris, L.J.; Long, X.Y.; Wei, Y.M.; Zheng, Y.L. and Ouellet, T. (2012). Effect of salicylic acid on Fusarium graminearum, the major causal agent of fusarium head blight in wheat. Fungal Biology, 116: 413-426. https://doi.org/10.1016/j. funbio.2012.01.001. 
Raskin, I.; Skubatz, H.; Tang, W. and Meeuse, B.J.D. (1990). Salicylic acid levels in thermogenic and non-thermogenic plants. Ann. Bot. 66: 369-373. doi: 10.1093/oxfordjournals.aob.a088037.

Rivas-San Vicente, M. and Plasencia, J. (2011). Salicylic acid beyond defence: its role in plant growth and development. J. Exp. Bot. 62, 3321-3338. doi: 10.1093/jxb/err031.

Safdar, A.; Javed, N.; Khan, S.A.; Khan, H.U.; Rehman, A. and Haq, I. (2010). Survey and investigation of different citrus growing areas for citrus sudden death syndrome. Pak. J. Phytopathol, 22(2): 71-78.

Shoala, T. (2018). Positive impacts of nanoparticles in plant resistance against different stimuli 267-279. In: "Nanobio-technology applications in plant protection" (Abd- -Elsalam, K.A. and Prasad, R. eds). $1^{\text {st }}$ ed. Springer International Publishing AG, part of Springer Nature.

Tilman, D.; Cassman, K.G.; Matson, P.A.; Naylor, R. and Polasky, S. (2002). Agricultural sustainability and intensive production practices. Nature, 418: 671-677. doi: 10.1038/nature01014.

Timmer, L. and Zitko, S. (1997). Evaluation of fungicides for control of Alternaria brown spot and citrus scab. Proceedings - Florida State Horticultural Society, 110: 71-76.

Vlot, A.C.; Dempsey, D.M.A. and Klessig, D.F. (2009). Salicylic acid, a multifaceted hormone to combat disease. Annu. Rev. Phytopathol., 47: 177-206. doi: 10.1146/annurev.phyto.050908.135202.

Yao, H. and Tian, S. (2005). Effects of pre- and post-harvest application of salicylic acid or methyl jasmonate on inducing disease resistance of sweet cherry fruit in storage. Postharvest Biology and Technology, 35: 253262.https://doi.org/10.1016/j.postharvbio.2004.09.001. 